\title{
Riesgo moral en la Garantía de Cumplimiento colombiana $^{1}$
}

\author{
AlexyX Villalba Mercado ${ }^{2}$
}

\section{RESUMEN}

Las garantías de cumplimiento se vuelven obligatorias en contratos de obra pública como 'solución' a los problemas de asimetría de la información y riesgo moral propios de dicho contrato; sin embargo, debe tenerse en cuenta que los seguros son en sí mismos fuente de riesgo moral. Por ello, es necesario establecer si las pólizas cuentan con el diseño adecuado para disminuir el riesgo moral, y con ello, mermar el riesgo de incumplimiento en los contratos.

En la parte analítica de este trabajo, se estudian datos empíricos y casos de incumplimiento, junto con el esquema obligatorio de la garantía de cumplimiento, y se logra establecer que, si bien la póliza protege el patrimonio del contratante en cualquier contingencia, puede que tenga efectos adversos en el contratista, ya que su diseño propicia el riesgo moral, la administración ineficiente de recursos y el incumplimiento.

Palabras clave: Garantía de cumplimiento; Contrato de obra pública, Riesgo moral, Problema de agencia administrativa; Asimetría de la información.

\section{ABSTRACT}

The surety bonds are mandatory in public infrastructure contracts as a 'solution' to the informational asymmetry problems and moral hazard inside of the said contract; however, we should note that insurance itself is a source of moral hazard. Therefore, it is necessary to found whether the policies have the proper design to reduce moral hazard, and thereby reduce the risk of contracts breach.

1 Fecha de recepción: 14 de febrero de 2020. Fecha de aceptación: 22 de abril de 2020. Para citar el artículo: Villalba Mercado, A. (2020). "Riesgo moral en la Garantía de Cumplimiento contractual", en Revista Con-Texto, n. ${ }^{\circ}$ 53, pp. 57-92. DOI https://doi.org/10.18601/01236458.n53.04

2 Abogada con orientación al Análisis Económico del Derecho y experiencia en asesoría jurídica, contratación y responsabilidad civil aplicada al sector de infraestructura pública. Egresada de la Universidad Sergio Arboleda, especialista en Derecho Privado Económico de la Universidad Nacional de Colombia y Máster en Análisis Económico del Derecho y Gestión Pública de EAE Business School. Correo-e: amvillalbam@gmail.com 
In the analytical part of this paper, we studied experiential data and cases where contractual breaches occur, with the mandatory surety bonds scheme, and as a result of that, we establish that, although the policy protects the contractor's assets of any contingency, it may have adverse effects on the contractor, since its design endorses moral hazard, inefficient management of resources and contract breaches.

Keywords: Surety Bonds; Public Infrastructure Contract; Moral Hazard; Administrative Agency Problem, Informational Asymmetry.

\section{INTRODUCCIÓN}

El Estado es un instrumento social, mediante el cual los asociados conciertan ceder parte de sus libertades a cambio de que les sean avalados sus derechos y de mantener la convivencia ${ }^{3}$.

Este organismo tendrá como fines esenciales "servir a la comunidad, promover la prosperidad general y garantizar la efectividad de los principios, derechos y deberes consagrados en la Constitución, facilitar la participación de todos en las decisiones que los afectan y en la vida económica, política, administrativa y cultural de la Nación; defender la independencia nacional, mantener la integridad territorial y asegurar la convivencia pacífica y la vigencia de un orden justo ${ }^{\prime 4}$, lo cual se traduce en la búsqueda del bien común.

No obstante, el Estado no tiene la capacidad de suplir cada una de las necesidades de los asociados por sí mismo por lo que es necesario acudir a servicios prestados por terceros; tal es el caso de los contratos de obra pública, en los que debido a la complejidad y especialidad que requieren, la administración opta por celebrar un contrato con un tercero para su ejecución.

Dicho contrato, desde el punto de vista económico, debe ser adjudicado teniendo en cuenta: (i) que el contratista tiene una propuesta con los mejores criterios costebeneficio, en este caso el beneficio será la calidad y experiencia en la prestación del servicio; (ii) que se realice un uso y aprovechamiento eficiente de los recursos de la administración y (iii) que el contrato sea lo más completo posible a fin de que se puedan prever posibles contingencias en la ejecución del mismo, como por ejemplo: que se incumpla el contrato, que no se obtengan los resultados esperados, o bien que los dineros no sean destinados a los fines previstos.

El primero de los criterios mencionados, puede garantizarse mediante un proceso de licitación bien estructurado. Sin embargo, los demás no se podrán comprobar efectivamente hasta que se lleve a cabo la obra, que, además, debido a la naturaleza de la prestación que se contrata, su ejecución se alarga en el tiempo. 
Por lo anterior, es necesario que la administración haga uso de mecanismos que le ayuden a proteger su patrimonio, frente a las posibles eventualidades en el contrato.

Es menester acotar que, de la correcta inversión del erario dependerá que la Administración pueda cumplir con sus fines, por lo que de ello se deriva que se mejoren las condiciones de vida de los asociados, que se atiendan otras necesidades sociales y, por supuesto, mantener el bienestar común, lo que a largo plazo se traduce en crecimiento económico del Estado; por ello, es indispensable que las garantías que se aporten con los contratos de obra no sean únicamente un mecanismo de protección patrimonial, sino que además puedan incentivar la correcta ejecución del contrato en los términos acordados.

\section{Problema}

¿Las garantías de cumplimiento usadas en contratos de obras públicas incentivan al cumplimiento y ayudan a reducir el riesgo moral de los contratistas?

\section{MARCO TEÓRICO}

\section{i. Contrato de obra y su riesgo}

Los contratos de obra pública son "los que celebren las entidades estatales para la construcción, mantenimiento, instalación y, en general, para la realización de cualquier otro trabajo material sobre bienes inmuebles" ${ }^{\prime \prime}$. El Estado se vale de este instrumento para suplir necesidades sociales que requieren un fortalecimiento de infraestructura, como facilitar la circulación en comunidades con población numerosa, o bien el mejoramiento de las vías de comunicación terrestre, fluviales o aéreas para facilitar el transporte de mercaderías y de personas, entre otras; no obstante, para el presente trabajo nos centraremos en vías terrestres.

Estos contratos tienen dos partes fundamentalmente: el contratante y el contratista. Quienes, para efectos del presente trabajo, consideramos personas racionales que buscan maximizar sus beneficios con la celebración del contrato, por lo que su actuar frente a la ejecución estará determinado por los medios que consideren necesarios para obtener la mayor cantidad de utilidad que les sea posible.

\section{El contratante}

En los contratos de obra pública, el contratante siempre será el Estado, que ostenta la propiedad de la obra, y está representado por una entidad pública a través de la cual manifiesta su voluntad; además, le corresponderá realizar el acompañamiento en todas

5 Numeral 1, artículo 32, Ley 80 de 1993 "Por la cual se expide el Estatuto General de Contratación de la Administración Pública", Colombia. 
las etapas contractuales: aprobar el diseño, la adjudicación del contrato a la oferta con la mejor relación coste-beneficio, asumir el coste, y cerciorarse de que la obra resultante sea de la calidad acordada.

Así bien, dado el rol del contratante y el objeto del contrato de obra mencionado en líneas anteriores, el Estado tendrá los siguientes intereses:

a. La ejecución efectiva de la obra, es decir, el cumplimiento del contrato de la manera que ha sido pactada, lo cual no necesariamente será la forma de ejecución más eficiente.

b. Obtener la mayor calidad que sea posible con el menor gasto. Para este caso, se entiende que una obra tiene calidad cuando suple las necesidades para la que fue concebida y además permanece estable en el tiempo.

c. Que la obra se lleve a cabo en poco tiempo.

Por lo tanto, la Utilidad Esperada para el contratante será: UeC0 =P (V-C)

Donde P representa la probabilidad de que se entregue la obra, $\mathrm{V}$ es la valoración que tiene el contratante de la obra y $\mathrm{C}$ el coste de llevar a cabo el contrato.

La valoración $(\mathrm{V})$ implica que la ejecución se ajuste a los parámetros que estableció en el contrato, en términos de calidad y tiempo. Mientras que espera que el coste (C) sea lo más bajo posible, es decir, que el gasto sea razonable y por supuesto que la probabilidad de ejecución (P) sea lo más alta posible. En este orden de ideas, y teniendo en cuenta los intereses del contratante, para que el contratante quiere celebrar el contrato la valoración debe ser superior al coste que le representa.

\section{El contratista}

De otra parte, tenemos al contratista, que puede ser una persona natural o jurídica a la que, luego de superar el proceso de selección y cumplir con las exigencias del contratante, se le adjudica la obra para su ejecución.

En términos técnicos, el contratista "es un especialista en su materia: su obligación es ejecutar los planos y de él se espera que los entienda perfectamente; que aplique las técnicas de construcción apropiadas y que deba conocer por razón de su oficio; que esté familiarizado con las especificaciones, usos, limitaciones y forma de aplicar los materiales, y que sepa administrar los riesgos" ${ }^{16}$.

Así mismo, el diseñador de la obra y el contratista, pueden ser o no la misma persona; la diferencia radica en que el primero se encarga de realizar los estudios pertinentes y establecer los parámetros necesarios para la ejecución. Mientras que el segundo se encarga de la construcción material de la obra según lo estipulado en los diseños.

6 Vallejo, Felipe (2007). "Responsabilidad Profesional en Cuanto a la Construcción de Obras" Revista Derecho del Estado, Colombia, p. 104. 
En cuanto a los intereses del contratista tenemos que son:

a. Ejecutar la obra y así poder cobrar el precio.

b. Maximizar sus beneficios patrimoniales: esto incluye un aumento del presupuesto, hasta el máximo posible que esté dispuesto a desembolsar el contratante y a su vez gastar lo menos posible. Sin embargo, no afirmamos que esta situación se presenta siempre; de hecho, estimamos que puede ser una excepción a la regla.

c. En cuanto al tiempo de ejecución del contrato, solo buscará aumentar el término si esto implica más gasto por parte del contratante.

Por lo tanto, la Utilidad Esperada del contratista se reduce a: UeC1 = P - C

Donde $\mathrm{P}$ representa el precio que recibirá el contratista como contraprestación por la obra. El valor de $\mathrm{P}$ dentro del contrato siempre debe ser mayor que el coste $(\mathrm{P}>\mathrm{C})$, para que el contratista quiera celebrarlo. Por lo que el contratista tiene dos opciones: o solicitar un precio muy elevado o tratar de disminuir los costes.

Por otra parte, C representa los costes en los que incurre el contratista para ejecutar la obra. Esto incluye: las exigencias contractuales que impone el contratante como gastos administrativos, pólizas de seguro, etc. (C1), y además lo que le cuesta realizar la obra contratada $(\mathrm{C} 2)$, es decir $\mathrm{C}=(\mathrm{C} 1+\mathrm{C} 2)$. La diferencia es que $\mathrm{C} 1$ no es renunciable en condiciones normales de ejecución, mientras que C2 dependerá de la forma en que el contratista decide ejecutar el contrato.

Entonces, tenemos que, si bien las partes tienen en común el interés de ejecutar el contrato, sus intereses individuales se contraponen: por una parte, el contratante esperará que el coste de la obra sea bajo con alta calidad, mientras el contratista buscará que la inversión por parte del Estado sea la mayor que esté dispuesto a hacer, y adicionalmente que la obra sea útil y funcional, aunque lo menos costosa que le sea posible.

Esta diferencia en la percepción de costes es especialmente importante, ya que la disminución de costes en las obras que desea conseguir el contratista implica una reducción: en los costes administrativos o bien en la calidad de los materiales de la obra, que además involucra una modificación de los parámetros establecidos en el contrato que haga menos costosa la obra y al mismo tiempo siga siendo funcional ${ }^{7}$; se podría, por ejemplo, disminuir $1 \mathrm{~cm}$ el grueso del asfalto. Intuitivamente esta parece una modificación minúscula; sin embargo, $1 \mathrm{~cm}$ de asfalto en una vía de $1.71 \mathrm{~km}^{8}$ representa una disminución de costes importante por el ahorro en materiales.

Así bien, no tiene iguales resultados la disminución de costes administrativos que en la calidad de la obra, ya que: el primero se descontaría directamente del precio, es decir, del patrimonio del contratista, y en ocasiones es muy dificultoso aminorar costes por este concepto, ya que los requerimientos administrativos son obligatorios para la ejecución del contrato. 
En cuanto a la disminución en costes de calidad, es cierto que el coste de llevar a cabo la obra no lo asume directamente el contratista; por el contrario, el contratante se encarga de la financiación del contrato. Sin embargo, es mucho más viable para el contratista hacer disminuciones en coste por este concepto, ya que estas modificaciones se pueden llevar a cabo sin que el contratante las perciba. Con ello, el contratista puede obtener un ahorro que no conoce el contratante, y por tanto es quien se beneficia de ello.

En suma, el coste de ejecución tiene que ser lo suficientemente bajo para que no implique una inversión adicional del patrimonio del contratista, y a su vez, lo suficientemente alto para que le permita aumentar su beneficio.

De lo expuesto, concluimos que existe un espectro de calidad en el que se puede mover el contratista durante la ejecución, en el que es posible disminuir la calidad de la obra, de tal manera que no sea perceptible para el contratante; el punto máximo de calidad del espectro será lo estipulado en el contrato y el diseño, mientras que el mínimo, que llamaremos Límite de tolerancia, es hasta donde el contratista puede salirse de los parámetros de calidad del contrato sin que se incurra en un incumplimiento, liberándose de indemnizaciones y sanciones administrativas.

Este Límite de tolerancia no es más que la manifestación de dos problemas inherentes al contrato de obra pública: la asimetría de información y el problema principal-agente.

\section{ii. Problemas principal-agente y asimetría de la información: analogía con el comportamiento burocrático (agencia administrativa)}

La asimetría de la información y el problema principal-agente se presentan entre las partes de un contrato de obra porque el contratante (principal), quien maneja los recursos y la financiación del proyecto, depende casi completamente del contratista (agente) para su ejecución, quien a su vez, al ser un profesional especializado, tendrá mayor conocimiento técnico de la obra, lo cual no es necesariamente un problema hasta que lo utiliza a su favor para aumentar los costos de ejecución, dilatar los términos del contrato y alterar su calidad, o, en otras palabras, para maximizar su beneficio.

Este choque de intereses se asemeja al modelo del comportamiento burocrático, también conocido como agencia administrativa, en el que el gestor de un servicio público busca maximizar su interés personal consiguiendo que el ordenador del gasto le asigne más presupuesto del que realmente necesita, aprovechándose del escaso conocimiento que este tiene sobre la gestión del servicio público 9 .

Debido a la semejanza de la relación contractual con la agencia administrativa, podemos extrapolarla a la situación en el contrato de obra, como se observa en la Figura 1:

9 Gamazo Chillón, Juan Carlos (s.f.). Comportamiento Burocrático y Presupuestación pública, Dirección General de Ciencia y Tecnología. Buenos Aires, Argentina. 
FIGURA 1. AGENCIA ADMINISTRATIVA EN EL CONTRATO DE OBRA PÚBLICA

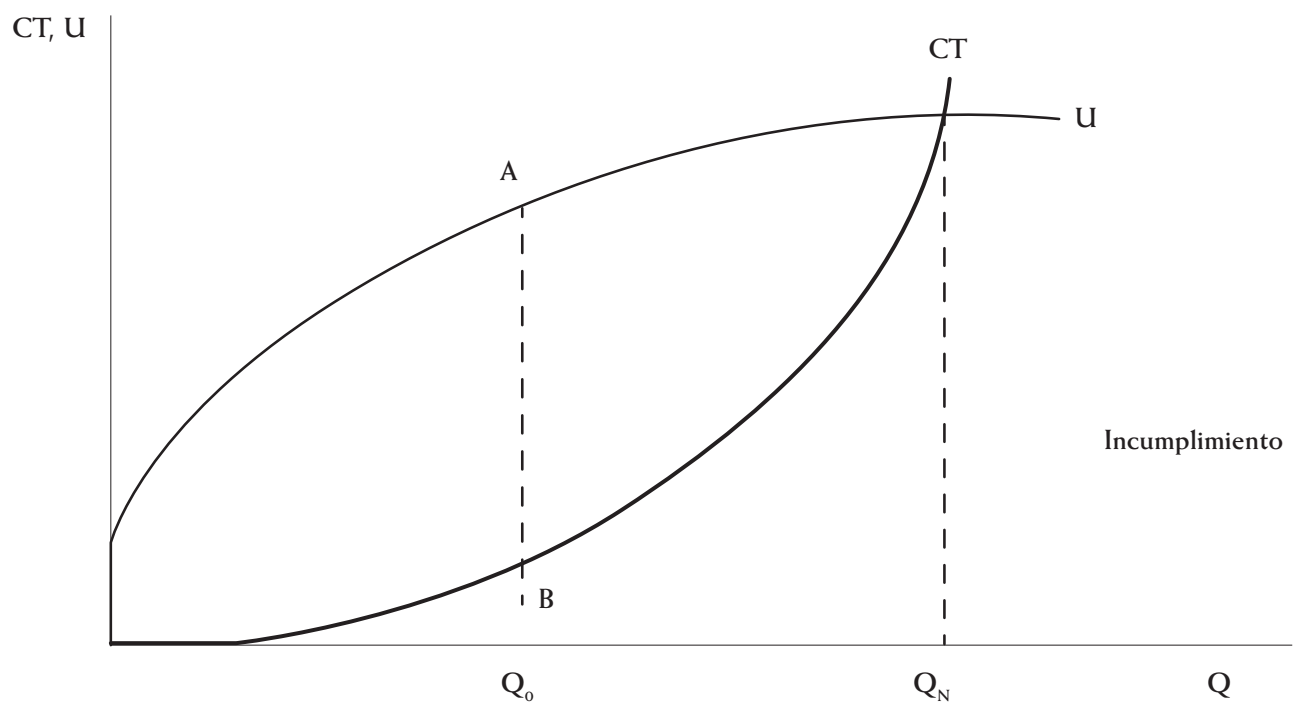

Fuente: Elaboración propia.

En el eje Y de la Figura 1 se mide el coste total (CT) invertido en la obra y la utilidad $(\mathrm{U})$; mientras que en el eje $\mathrm{X}$ se mide la cantidad de output obtenido $(\mathrm{Q})$ dependiendo de la cantidad de inversión.

Entonces, tenemos que $\mathrm{AB}$ señala los puntos más distantes entre las curvas de utilidad y coste total, es decir que en Q0 se obtendrá el mayor nivel de utilidad con el menor coste invertido posible. Mientras que en QN se encuentra el punto de intersección entre la curva de coste total, que ha aumentado exponencialmente, con la curva de utilidad que empieza a decrecer; es aquí donde se ubica el límite de tolerancia, ya que se alcanza el mayor coste posible sin que haya una pérdida de utilidad, entendiendo que el detrimento en la utilidad es un incumplimiento contractual.

Así, como el interés del contratista es obtener el mayor beneficio posible, tratará de ubicar al contratista en el punto $\mathrm{QN}$, ya que es donde se obtiene el mayor volumen presupuestario sin incurrir en pérdidas; sin embargo, se encuentra muy cerca del incumplimiento. Mientras que el interés del contratante se ubicará en el punto Q1. En consecuencia, la diferencia entre el punto Q0 y el QN, representa el exceso de presupuesto que se invertido: $\mathrm{DQ}=\mathrm{Q} 0-\mathrm{QN}$

Es decir que la agencia administrativa aumenta el nivel de riesgo del contrato, ya que el contratista ve la posibilidad de que su utilidad puede aumentar valiéndose de la asimetría de la información con el contratante, lo que hace que el contratista se ubique en el límite de tolerancia, donde logra aumentar la inversión en detrimento del contratante. 
De esta situación se desprenden un problema muy importante ${ }^{10}$ : el riesgo moral.

\section{RIESGO MORAL}

El concepto económico del riesgo moral establece que el actuar de un individuo será más o menos arriesgado en cuanto las posibles consecuencias de sus acciones no recaigan sobre ellos mismos, sino sobre terceros ${ }^{11}$.

Este fenómeno se presenta en el contrato de obra pública en dos facetas:

\section{i. El riesgo moral en la agencia administrativa}

En este caso, el riesgo moral surge de la asimetría en el acceso a la información que existe entre las partes:

a) El contratista: como se ha mencionado, es un profesional con conocimiento en la materia, e incluso su responsabilidad frente al contratante está ligada a su nivel de experticia en el ejercicio de su profesión. Este conocimiento le da una ventaja importante, que no posee el contratante ${ }^{12}$.

Incluso, si se presenta la situación de que el mismo contratista realiza el diseño y la obra, su conocimiento es aún más profundo en los detalles de la ejecución.

b) El contratante: su experticia no se centra en la construcción de obras, por lo que no participa directamente de la ejecución material del contrato.

Esta diferencia de información entre las partes es el principal problema que presenta inherentemente el contrato de obra, ya que propicia que el contratista pueda maximizar sus beneficios en detrimento del patrimonio del contratante, aumentando el riesgo del contrato, así:

- El contratante hará una inversión mucho mayor a lo que es realmente necesario, es decir, se propicia una administración ineficiente de recursos.

- La calidad de la obra entregada puede ser mucho menor a la acordada en el contrato.

- Existe un aumento del riesgo de incumplimiento, ya que, si el contratista centra su actuar en la maximización de sus intereses manteniéndose en el límite de tolerancia, la disminución tanto en los parámetros de los contratos y como de la utilidad lo mantienen muy cerca del umbral del incumplimiento.

10 Ibídem, p. 150.

11 Krugman, Paul y Wells, Robin (2006). Introducción a la economía: Microeconomía, Editorial Reverté, p. 448 .

12 Vallejo, Felipe (2007). "Responsabilidad Profesional en Cuanto a la Construcción de Obras" Revista Derecho del Estado Colombia. 
Ahora bien, para revertir el efecto del riesgo moral en la agencia administrativa, se puede recurrir a varios mecanismos: el aumento del precio, para que no sea necesario disminuir los costes, monitoring (interventoría), o bien la inclusión de seguros que ayuden a garantizar el cumplimiento del contrato.

De los tres mecanismos mencionados, consideramos que el contrato de seguro es el que más se ajusta a las necesidades del contratante porque no aumenta el valor de la inversión, como sí sucede con el incremento del precio y el monitoring, ya que el coste extra ocasionado por la póliza (en teoría) recae en el contratista ${ }^{13}$; adicionalmente, un seguro ayuda al contratante a anticiparse al posible actuar del contratista en pro de sus intereses personales y cuantifica anticipadamente los daños y perjuicios que puede suscitar el problema de agencia administrativa ${ }^{14}$.

Sin embargo, en dado caso que se exija una póliza para la ejecución, la compañía de seguros se convierte en otro interviniente en la relación contractual, que celebra el contrato con el fin de aumentar su beneficio, por lo que tendrá sus propios intereses frente a la ejecución, como son:

a. Que el contratista cumpla el contrato y no quede inmerso en ninguna causal para siniestrar la póliza.

b. Que se mantenga el nivel de riesgo más bajo posible (o bien, el mismo que había al momento de contratar).

Esto nos indica que el contrato de seguro es un mecanismo idóneo para reducir los niveles de riesgo en la ejecución del contrato, por dos razones: en primer lugar, quien asume el coste del daño que acarrea la ocurrencia del siniestro es la compañía de seguros, por lo que le representa un detrimento patrimonial; y en segundo lugar, existe una razón de competencia, en el sentido que, si una compañía asegura un acto con muy poco riesgo, o bien encontrar un mecanismo de prevención del riesgo muy económico, puede ofrecer pólizas de menos coste con grandes coberturas ${ }^{15}$, por lo que, en suma, el hecho de que la compañía de seguros decida actuar conforme sus intereses es más beneficioso para el contratante y puede que, ceteris paribus, ayude a promover el cumplimiento.

Empero, el contrato de seguros puede presentar, a su vez, varios inconvenientes:

El primero es un problema de diseño, ya que las pólizas de seguro, dependiendo del tipo de cubrimientos, cláusulas y prohibiciones que contengan, pueden tener efectos adversos.

13 Existe la posibilidad de que, si el contratante incluye el coste del seguro, el contratista incremente el precio.

14 Rodríguez-Arana Muñoz, Jaime y Álvarez Bairbeto, Francisco Javier (1997). El régimen de las garantías para contratar con la administración pública, Actualidad Administrativa, España.

15 Omri, Ben-Shahar \& Kyle D. Logue (2012). "Outsourcing Regulation: How Insurance Reduces Moral Hazard", Michigan Law Review 197, p. 203. 
Como por ejemplo en el contexto del contrato de obra pública:

1. Si una póliza es demasiado garantista en términos de calidad frente al contratista, es posible que este se mantenga en el límite de tolerancia. Lo cual aumenta el riesgo de incumplimiento.

2. Podría también ser lo suficientemente garantista para que, en caso de incumplimiento del contrato, la aseguradora sea la que asuma el daño y el contratista se vea completamente liberado de su responsabilidad patrimonial, lo que representa un incremento del riesgo moral.

3. Puede que sea lo bastante restrictiva en términos de calidad para hacer que ambas partes se mantengan en el mismo nivel de utilidad y gasto, y a su vez endilgar responsabilidad patrimonial al contratista en caso de incumplimiento.

El segundo problema que se presenta es que el contrato de seguros, al igual que el contrato de obra, es en sí mismo una fuente de riesgo moral.

\section{ii. Riesgo moral en las pólizas de seguros de contratos obras}

Cuando el adquirente de una póliza se ve liberado de su responsabilidad patrimonial frente a posibles incumplimientos en la ejecución del contrato y la traslada a la aseguradora, no va a tomar medidas de precaución para evitar la ocurrencia del siniestro ${ }^{16}$; este sería el riesgo moral en los seguros.

No obstante, este problema se puede solucionar mediante la asignación de deducibles, también llamado franquicia por algunos autores. Se trata de una figura propia de los contratos de seguros por medio de la cual se hace partícipe del daño al asegurado, a fin de que, al asumir parte del riesgo, invierta más en precaución y así se disminuye la probabilidad de que ocurra el siniestro. El deducible se pacta entre las partes al momento de celebrar el contrato ${ }^{17} 15$ y puede ser de diversas formas:

Entre las modalidades de deducibles podemos encontrar:

i) El porcentaje que se fija sobre el valor de la pérdida o sobre el valor asegurable o valor asegurado; su finalidad es la de procurar que el asegurado mantenga las medidas preventivas tendientes a evitar la ocurrencia de siniestros.

ii) El valor absoluto: se establece una suma única como valor mínimo que será asumida por el asegurado en cualquier siniestro.

iii) El combinado: modalidad más usada en la cual se establece un porcentaje que motive al asegurado a mantener la diligencia en el manejo de los riesgos y un mínimo tendiente a evitar desgastes administrativos.

16 Cohen, Alma \& Dehejia, Rajeev (2004). The Effect Of Automobile Insurance and Accident Liability Laws On Traffic Fatalities, J. L. \& ECON. 357.

17 López Saavedra, Domingo (2008). Revista de responsabilidad civil y seguros: publicación mensual de doctrina, jurisprudencia y legislación, pp. 45-50. 
iv) Franquicia: se establece un valor hasta por el cual el asegurado asumirá cualquier pérdida, pero si la cuantía del siniestro es superior a dicho valor, la aseguradora pagará el $100 \%$.

v) Deducibles agregados: se conviene un valor hasta el cual el asegurado asumirá las pérdidas que se presenten durante la vigencia del seguro, cuyas cuantías se van acumulando y, en caso de que este acumulado alcance el deducible pactado, la aseguradora asumirá el $100 \%$ de las pérdidas que se presenten de ahí en adelante ${ }^{18}$.

No obstante, para que este sistema de fianzas y deducibles funcione, hay que tener en cuenta:

a) La capacidad financiera del contratista: el patrimonio influye en la forma en que las personas asumen los riesgos. En el sentido de que el seguro tiene como finalidad proteger un patrimonio; no obstante, si una persona no tiene un patrimonio que perder se volverá más propensa al riesgo. Por lo que el mecanismo de hacerlo partícipe del riesgo no va a tener ningún efecto $y$, en consecuencia, esta persona no va a tratar de prevenir el siniestro y tampoco disminuirá el riesgo moral.

b) Facilidad para declararse en quiebra: un sistema jurídico que permite la facilidad de declararse insolvente puede tener los mismos efectos de no contar con capacidad financiera. Por lo que tampoco serviría los mecanismos habituales para afrontar el riesgo moral.

En suma, se podría afirmar que el riesgo moral en los contratos de seguro puede ser subsanado mediante el diseño de la misma garantía, como, por ejemplo, estableciendo un monto de deducible que haga más costoso para el contratista el incumplimiento. Sin embargo, continúa siendo un problema la debilidad de las instituciones que puede facilitar las vías de exoneración al contratista.

\section{HIPÓTESIS}

Los contratos de obra pública son una fuente de riesgo moral en sí mismos, por lo que tienen un alto grado de riesgo de incumplimiento (el contratista se encuentra en el límite de tolerancia). Es por ello que la mayoría de las legislaciones incluyen garantías de cumplimiento obligatorias.

Sin embargo, del diseño de la póliza dependerá su efecto: puede reducir notablemente el problema del riesgo moral, o puede tener un impacto no deseado, como propiciar el incumplimiento del contratista.

Este panorama se aplicará en el caso colombiano, que tiene dos problemas fundamentalmente: i) un alto grado de atraso en calidad y desarrollo de infraestructura y ii) 
un nivel importante de pérdidas en la contratación estatal debido a incumplimientos contractuales.

Nuestra hipótesis es que la garantía de cumplimiento diseñada por el gobierno colombiano es demasiado garantista y sobreprotectora con los contratistas, por lo que están consiguiendo un efecto adverso, que es aumentar el problema del riesgo moral y con ello aumenta los niveles de incumplimiento en detrimento del erario y un aprovechamiento ineficiente de los recursos. Es por ello que debe cambiar la estructura de la póliza y migrar de asumir el incumplimiento patrimonialmente a materialmente.

Método: debido a la dificultad en la obtención de datos claros y detallados respecto del estado de los contratos de obra celebrados en Colombia, utilizaremos un método empírico-analítico.

Fuente de información: se utilizarán datos que reflejen la realidad actual de la contratación pública de obras en Colombia y de la estructura de la garantía obligatoria de cumplimiento.

Metodología: se hará un análisis económico del clausulado, cubrimiento y el mecanismo para hacer efectiva de la garantía de cumplimiento, a fin de establecer cuáles de dichas partes incrementan el problema del riesgo moral, y deben ser modificadas para optimizar su eficacia, finalizando con una propuesta de mejora.

\section{CASO COLOMBIANO}

\section{i. Nivel de desarrollo de infraestructura}

Según los datos aportados en The Global Competitiveness Report 2018 del Foro Económico Mundial, Colombia ocupa el puesto $60^{[19]}$ entre 140 países en economías competitivas. Dentro de este estudio se tuvieron en cuenta factores como: Instituciones (fortaleza y corrupción), sanidad, sistema financiero, innovación, infraestructura, entre otros.

Se observa que en infraestructura Colombia se encuentra ubicada en el puesto 63 de 140 países, dentro de este pilar el Foro Económico Mundial tuvo en cuenta "la calidad y extensión de la infraestructura de transporte (carreteras, vías férreas, transporte fluvial y aéreo) y la infraestructura de los servicios públicos" 20 , que dividió a su vez en los siguientes componentes que calificó individualmente (ver tabla 1).

19 "The Global Competitiveness Report 2018: Insight report", World Economic Forum, 2019, p. 163.

20 Ibídem, p. 39. 

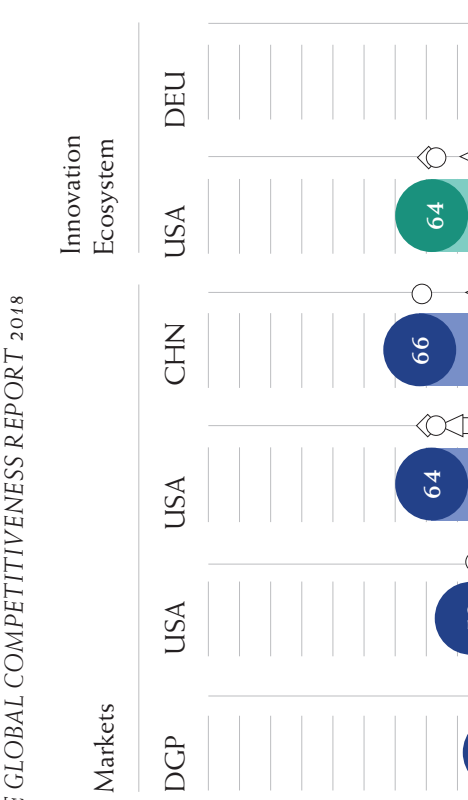

$\stackrel{3}{3}$

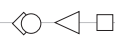

\section{अ}

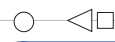

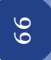

$<0<$

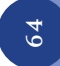

仓ิ

Z

焉葶

હิ

$\stackrel{0}{0}$

ชิ

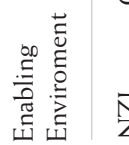

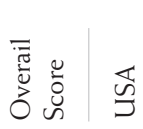

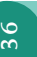

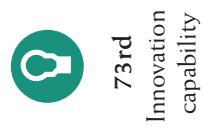

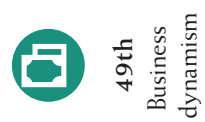

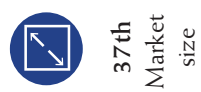

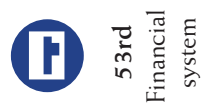

مَ

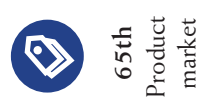

IX) 营言

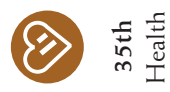

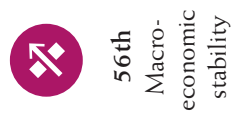

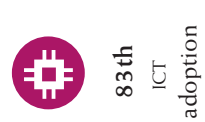

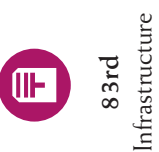

(E)

(2) 0 营

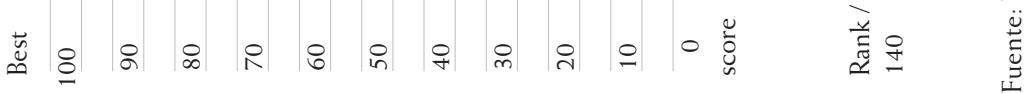


TABLA 1: CALIFICACIÓN DESGLOSADA DE LA INFRAESTRUCTURA COLOMBIANA

\begin{tabular}{|l|c|c|c|}
\hline \multicolumn{1}{|c|}{ Componente } & Valor* & Puntaje** & Rank*** \\
\hline 1 Índice de conectividad vial 0-100 (best) & 47.9 & 47.9 & 97 \\
\hline 2 Calidad de carreteras 1-7 (best) & 3.3 & 37.9 & 102 \\
\hline $\begin{array}{l}\text { 3 Densidad de carreteras ferroviarias km de carreteras / } \\
\text { km cuadrados }\end{array}$ & 1.5 & 3.7 & 92 \\
\hline 4 Eficiencia de los servicios de trenes 1-7 (best) & 1.8 & 12.5 & 125 \\
\hline 5 Puntuación de conectividad del aeropuerto & $144,423.40$ & 68.7 & 31 \\
\hline 6 Eficiencia de los servicios de transporte aéreo1-7 (best) & 4.4 & 56.4 & 80 \\
\hline 7 Eficiencia de los servicios portuarios 1-7 (best) & 4 & 49.6 & 72 \\
\hline
\end{tabular}

Fuente: World Economic Forum, Executive Opinion Survey.

* Es el indicador de valor para la economía del país.

** Depende del margen que se establece para cada variable, señalado en la tabla.

*** Posición que ocupa Colombia entre 140 países por la valoración de cada variable (resaltado propio).

Para el desarrollo del presente trabajo nos enfocaremos en la infraestructura de carreteras, cuyo puntaje, si bien no tiene la menor valoración entre todas las variables ${ }^{21}$, sí es considerablemente bajo en comparación con la infraestructura fluvial y aérea.

De hecho, con la calificación otorgada, si se compara la calidad de las carreteras colombianas con la de los demás países latinoamericanos y del Caribe, Colombia es el número 14 entre los 21 países estudiados. En dicha escala, el mejor es Chile, con una puntuación de 5,2 sobre 7, mientras que el último en la lista es Haití, con una puntuación de 2,0 sobre 7 .

TABLA 2. POSICIÓN DE COLOMBIA ENTRE LOS PAÍSES LATINOAMERICANOS Y DEL CARIBE

\begin{tabular}{|c|c|c|}
\hline Ranks / 140 & Country / Economy & Score 1-7 (best) \\
\hline 24 & Chile & 5.2 \\
\hline 31 & Ecuador & 5.0 \\
\hline 47 & Mexico & 4.5 \\
\hline 53 & Dominican Republic & 4.4 \\
\hline 56 & Panama & 4.3 \\
\hline
\end{tabular}

21 Es de tener en cuenta que Colombia no es un país que invierta especialmente en el fortalecimiento de su infraestructura ferroviaria; de hecho, tiene una longitud total de redes férreas de $3.304 \mathrm{~km}$ (Fuente: Instituto Nacional de Vías, Colombia), lo cual no es abundante para un país con una superficie total de $1.142 .748 \mathrm{~km}^{2}$. 


\begin{tabular}{|c|c|c|}
\hline Ranks / 140 & Country / Economy & Score 1-7 (best) \\
\hline 60 & Nicaragua & 4.2 \\
\hline 65 & Honduras & 4.1 \\
\hline 66 & El Salvador & 4.0 \\
\hline 72 & Jamaica & 3.9 \\
\hline 73 & Trinidad and Tobago & 3.9 \\
\hline 93 & Argentina & 3.4 \\
\hline 98 & Bolivia & 3.4 \\
\hline 99 & Uruguay & 3.3 \\
\hline 102 & Colombia & 3.3 \\
\hline 108 & Peru & 3.2 \\
\hline 112 & Brazil & 3.0 \\
\hline 121 & Venezuela & 2.8 \\
\hline 124 & Costa Rica & 2.7 \\
\hline 128 & Guatemala & 2.6 \\
\hline 129 & Paraguay & 2.5 \\
\hline 139 & Haiti & 2.0 \\
\hline
\end{tabular}

Fuente: World Economic Forum, Executive Opinion Survey.

De igual forma, si se hace una comparación global de la calidad de carreteras, los países que obtuvieron un puntaje igual a Colombia, y por lo tanto comparten el mismo nivel de calidad vial, son los siguientes:

TABLA 3. POSICIÓN DE COLOMBIA A NIVEL GLOBAL

\begin{tabular}{|c|c|c|}
\hline Ranks / 140 & Country / Economy & Score 1-7 (best) \\
\hline 99 & Uruguay & 3.3 \\
\hline 100 & Cambodia & 3.3 \\
\hline 101 & Cóte d'lvoire & 3.3 \\
\hline 102 & Colombia & 3.3 \\
\hline 103 & Ethiopia & 3.3 \\
\hline
\end{tabular}

Fuente: World Economic Forum, Executive Opinion Survey. 
De la tabla se vislumbra que Colombia comparte el mismo nivel de calidad en infraestructura vial con países como Etiopía y Costa de Marfil22, que ocuparon los puestos $122^{[23]}$ y $114^{[24]}$, respectivamente, en el ranking de economías competitivas. Es decir que el nivel de calidad está muy por debajo de lo esperado para una economía que se considera mucho más competitiva.

Esta deficiencia de calidad puede tener dos posibles orígenes: i) Colombia no ha estado invirtiendo lo suficiente en el desarrollo de la infraestructura vial o ii) se ha hecho la inversión, pero esta no es eficiente y hay un nivel alto de incumplimiento.

\section{ii. Contratación de obras públicas en Colombia}

En primer lugar, es necesario establecer si el Estado colombiano ha dado mucha más importancia al desarrollo de la infraestructura vial o de carreteras en los últimos años, gestión que se ha realizado a través del Instituto Nacional de Vías - Invías ${ }^{25}$.

Empero, para poder establecer si la inversión ha sido suficiente, es necesario establecer un término de estudio amplio para observar la evolución presupuestal, por lo que en el caso que nos atañe tomaremos el término comprendido entre el 24 de noviembre de 2014 y el 28 de junio de 2018.

Dentro de la siguiente tabla se observa la inversión total realizada por la nación, y el estado de la obra adjudicada al 28 de junio de 2018 :

TABLA 4. ESTADO DE LA CONTRATACIÓN PÚBLICA EN COLOMBIA

\begin{tabular}{|l|c|c|c|c|c|}
\hline \multicolumn{1}{|c|}{$\begin{array}{c}\text { Modalidad de } \\
\text { contratación* }\end{array}$} & $\begin{array}{c}\text { Contratos } \\
\text { adjudicados }\end{array}$ & $\begin{array}{c}\text { Contratos en } \\
\text { proceso }\end{array}$ & $\begin{array}{c}\text { Contratos } \\
\text { ejecutados }\end{array}$ & Inversión & Vigencia \\
\hline Contratación directa & - & 3 & 3 & $3,278,869.30 €$ & Año 2014 \\
\hline Licitación & 2 & & 2 & $207,211.31 €$ & $\begin{array}{c}(24 \text { nov - } \\
\text { dic })\end{array}$ \\
\hline Selección Abreviada & 1 & 6 & 6 & $3,496,921.92 €$ & \\
\hline Mínima Cuantía & 6 & & & $10,841.31 €$ & \\
\hline Subtotal & & & & \\
\hline
\end{tabular}

Aparece dentro de la tabla como Côte d'Ivoire.

"The Global Competitiveness Report 2018: Insight report", World Economic Forum, 2019, p. 219.

"The Global Competitiveness Report 2018: Insight report", World Economic Forum, 2019, p. 175.

Decreto 2171 del 30 de diciembre de 1992, que creó un establecimiento público del orden nacional, con personería jurídica, autonomía administrativa y patrimonio propio, adscrito al Ministerio de Transporte, que tuviera como objetivo ejecutar las políticas y proyectos relacionados con la infraestructura vial a cargo de la Nación. 


\begin{tabular}{|c|c|c|c|c|c|}
\hline $\begin{array}{l}\text { Modalidad de } \\
\text { contratación* }\end{array}$ & $\begin{array}{l}\text { Contratos } \\
\text { adjudicados }\end{array}$ & $\begin{array}{c}\text { Contratos en } \\
\text { proceso }\end{array}$ & $\begin{array}{l}\text { Contratos } \\
\text { ejecutados }\end{array}$ & Inversión & Vigencia \\
\hline Contratación directa & 2 & & 2 & $495.650 .25 €$ & \multirow{5}{*}{$\begin{array}{l}\text { Año } 2015 \\
\text { (01 enero } \\
\text { - } 31 \text { dic.) }\end{array}$} \\
\hline Licitación & 88 & 43 & 45 & $869,513,039.25 €$ & \\
\hline Selección Abreviada & 181 & 1 & 180 & $15,183,849.60 €$ & \\
\hline Mínima Cuantía & 64 & & 64 & $811,828.63 €$ & \\
\hline Subtotal & 335 & 44 & 291 & $885,508,717.48 €$ & \\
\hline Contratación directa & 1 & & 1 & $1,423,632.22 €$ & \multirow{5}{*}{$\begin{array}{c}\text { Año } 2016 \\
\text { (01 enero } \\
\text { - } 31 \text { dic) }\end{array}$} \\
\hline Licitación & 292 & 61 & 231 & $98,110,893.16 €$ & \\
\hline Selección Abreviada & 430 & 23 & 407 & $2,781,192.15 €$ & \\
\hline Mínima Cuantía & 221 & & 221 & $2,515,345.74 €$ & \\
\hline Subtotal & 944 & 84 & 860 & $104,831,063.27 €$ & \\
\hline Contratación directa & 4 & 1 & 3 & $262,939.67 €$ & \multirow{3}{*}{$\begin{array}{c}\text { Año } 2017 \\
\text { (01 enero } \\
\text { - } 31 \text { dic.) }\end{array}$} \\
\hline Licitación & 53 & 34 & 19 & $201,890,451.89 €$ & \\
\hline Selección Abreviada & 120 & 11 & 109 & $9,889,107.94 €$ & \\
\hline Mínima Cuantía & 117 & 11 & 106 & $136,975,186.86 €$ & \\
\hline Subtotal & 294 & 57 & 237 & $349,017,686.36 €$ & \\
\hline Contratación directa & 4 & 4 & & $4,288,189.16 €$ & \multirow{5}{*}{$\begin{array}{c}\text { Año } 2018 \\
\text { (01 enero } \\
-28 \text { junio) }\end{array}$} \\
\hline Licitación & 18 & 18 & & $26,810,019.07 €$ & \\
\hline Selección Abreviada & 78 & 78 & & $4,575,967 €$ & \\
\hline Mínima Cuantía & 122 & 103 & 19 & $1,411,965.24 €$ & \\
\hline Subtotal & 222 & 203 & 19 & $37,086,140.47 €$ & \\
\hline Total General & 1801 & 388 & 1413 & $1,379,940,52$ & $9.50 €$ \\
\hline
\end{tabular}

Fuente: Tabla de elaboración propia con datos de Acta Informe de Gestión, Carlos Alberto García Montes 2018 - Instituto Nacional de Vías.

* Se señala el tipo de contratación porque cada tipo se utilizará dependiendo (en parte) de la cuantía del contrato.

De la anterior tabla se observa que la inversión ha sido cuantiosa y se adelanta un número importante de obras anualmente; no obstante, el monto que se emplea no ha sido constante, sino que ha oscilado en cada vigencia, lo cual probablemente se debe a que la inversión del Estado depende de la necesidad, del presupuesto asignado a la entidad, del plan de ordenamiento territorial, entre otras razones. 
Entonces, tenemos que al final de la vigencia al 28 de junio de 2018, el estado total de las obras es:

GRÁFICO 2. CONTRATOS DE OBRA SEGÚN SU ESTADO (\%)

\begin{tabular}{|l|c|}
\hline & Total \\
\hline $\begin{array}{l}\text { Contratos de obra } \\
\text { pública en adjudicados }\end{array}$ & $\begin{array}{c}1801 \\
(100 \%)\end{array}$ \\
\hline $\begin{array}{l}\text { Contratos de obra } \\
\text { pública en proceso }\end{array}$ & $\begin{array}{c}388 \\
(22 \%)\end{array}$ \\
\hline $\begin{array}{l}\text { Contratos de obra } \\
\text { pública ejecutados }\end{array}$ & $\begin{array}{c}1413 \\
(66 \%)\end{array}$ \\
\hline
\end{tabular}

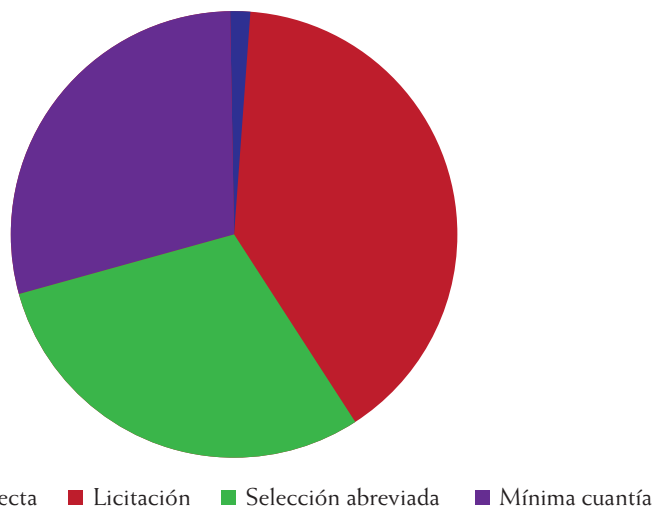

Tenemos entonces que un $66 \%$ de los contratos están ejecutados, es decir que han sido liquidados, entregados y recibidos de forma exitosa por la entidad estatal, y adicionalmente, no están incursos en sanciones ni procesos judiciales por su ejecución.

Por otra parte, si bien el $22 \%$ no es un porcentaje demasiado significativo de contratos en ejecución, se observa que la mayor parte de ellos corresponde a contratos seleccionados a través de licitación, que además son los que tienen una mayor inversión.

GRÁFICO 3. CONTRATOS DE OBRA POR MECANISMO DE SELECCIÓN (\%)

\begin{tabular}{|l|c|c|}
\hline Contratación directa & 5 & $1.30 \%$ \\
\hline Licitación & 156 & $40 \%$ \\
\hline Selección abreviada & 113 & $29 \%$ \\
\hline Mínima cuantía & 114 & $29.40 \%$ \\
\hline
\end{tabular}

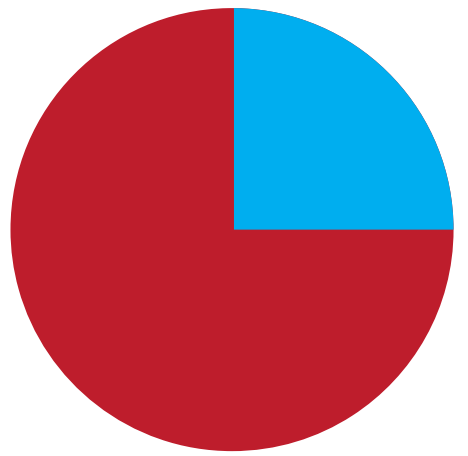

- Contratos de obra pública en proceso Contratos de obra pública ejecutados

Ahora bien, los contratos pueden encontrarse en proceso por diferentes razones: porque aún se encuentran en el término estipulado para ejecución, porque se ha iniciado un proceso sancionatorio, porque se encuentran inmersos en un proceso judicial, porque se han realizado prórrogas o por razones ambientales. 
Infortunadamente, el informe que nos ha servido como base de información no contiene una relación de la causa por la que los contratos se encuentren en proceso; sin embargo, contiene los siguientes datos sobre los procesos sancionatorios y judiciales que están en curso a 28 de junio de 2018, lo cual nos puede dar una idea de la cantidad de contratos que se encuentran pausados por estas razones:

TABLA 5. PROCESOS SANCIONATORIOS INVÍAS

Procedimientos administrativos con sanción o archivados:

Se han tramitado 45 Procedimientos administrativos Sancionarios con sanción o archivados

Procedimientos administrativos activos:

Se están tramitando 28 Procedimientos administrativos sansonatorios en trámite

Fuente: Acta Informe de Gestión, Carlos Alberto García Montes 2018 - Instituto Nacional de Vías.

De la tabla 1 tenemos que iniciaron 45 procesos sancionatorios que ya se han culminado. Sin embargo, no se establece cuántos de ellos terminaron en sanción. Además, hay 28 procesos sancionatorios en curso. Es decir que ha sido necesario iniciar 73 procesos sancionatorios porque ha existido riesgo de incumplimiento, teniendo en cuenta que el Proceso Administrativo Sancionatorio tiene como finalidad conminar al contratista al cumplimiento, más que llegar a una sanción en sí.

TABLA 5. PROCESOS JUDICIALES CON INVÍAS COMO DEMANDADO

\begin{tabular}{|l|r|r|}
\hline \multicolumn{1}{|c|}{ Acción/Medio de control } & N. & \multicolumn{1}{c|}{ Pretensión } \\
\hline Reparación directa & 2148 & $\$ 2,523,863,266,175,00$ \\
\hline Controversias contractuales & 258 & $\$ 707,183,110,410,00$ \\
\hline Nulidad y restablecimiento del derecho & 102 & $\$ 88,017,911,696,00$ \\
\hline Nulidad simple & 9 & \\
\hline Constitucional & 380 & $\$ 1,541,567,957,055,00$ \\
\hline Ejecutivos & 76 & $\$ 45,436,529,836,00$ \\
\hline Repetición & 2 & $\$ 20,000,000,00$ \\
\hline Civil & 32 & $\$ 7,588,254,462,00$ \\
\hline Administración & 6 & $\$ 833,910,303,00$ \\
\hline Laboral & 248 & $\$ 17,356,940,566,00$ \\
\hline Total de procesos administrativos & 3261 & $\$ 4,931,867,880,503,00$ \\
\hline
\end{tabular}

Fuente: Acta Informe de Gestión, Carlos Alberto García Montes 2018 - Instituto Nacional de Vías (valores en cop). 
En estas tablas se observan los procesos judiciales adelantados contra el Instituto, y tendremos en cuenta solo los procesos de nulidad y restablecimiento del derecho ${ }^{26}$, ya que es el mecanismo con el que se hace control de legalidad a los actos administrativos sancionatorios que fueron saldados por la aseguradora; estos suman un total de 102 acciones.

El hecho de que existan tantos procesos iniciados por nulidad de resoluciones nos indica que el proceso sancionatorio no ha sido tan eficiente al momento de prevenir la ocurrencia del riesgo, y que hay un alto grado de incumplimiento.

Además, se debe tener en cuenta que, si bien la cantidad puede no ser demasiado exagerada, es necesario contrastar esta situación con el coste que puede acarrear.

\section{iii. Ejemplos de incumplimiento en Colombia}

A continuación, expondremos brevemente varios casos puntuales en los que se evidencia la tardanza en el incumplimiento de los contratos de obras y el detrimento que ello genera en el Estado colombiano.

1. El Túnel de la Línea

Esta es una de las obras más controversiales en Colombia. Tiene una extensión de 8,65 km., y es un túnel que permitirá cruzar la Cordillera Central de los Andes.

Este contrato fue adjudicado en el 2008 (Contrato de Obra 3640 de 2008), y actualmente, no solo no se ha finalizado, sino que cuenta con una sanción de caducidad $^{27}$ (incumplimiento definitivo) por valor de $15.589,68 €$, una sanción por incumplimiento parcial ${ }^{28}$ por valor de $4.191 .869,30 €$, y por último una sanción ambiental ${ }^{29}$ por valor de $890.940,37 €$.

La Inversión total que ha hecho el Estado colombiano por la obra es de \$2,2 billones de $\operatorname{pesos}^{30}$, que equivale aproximadamente a $571.621 .600 .000 €$, por lo que los organismos de control fiscal han iniciado una investigación en contra de los directivos del Instituto Nacional de Vías - Invías, la Corporación Autónoma

26 Dentro del "Acta Informe de Gestión", Carlos Alberto García Montes 2018 - Instituto Nacional de Vías, en la página 556 se establece que los procesos de Nulidad se iniciaron por motivos de prima técnica, mientras que los de Nulidad y Restablecimiento del Derecho son por nulidad de resoluciones.

27 Economía y Negocios, "Invías caducó el contrato del túnel de la línea" https://www.eltiempo.com/archivo/ documento/CMS-15153395, periódico El Tiempo, 27 de enero 2015, 07:31 a.m. Consultado agosto 2019. Español.

28 Resolución n. 08443 del 29 de noviembre de 2016, Proferida por el Instituto Nacional de Vías.

29 Resolución n. 756 del 11 de mayo de 2015, Proferida por el Instituto Nacional de Vías.

30 Alfonso, Katherin (2018). "Inversión en Túnel de la Línea va en \$2,2 billones, según el Invías" https://www. larepublica.co/economia/inversion-en-tunel-de-la-linea-va-en-22-billones-2590622, periódico La República, 22 de enero de 2018. Consultado agosto 2019. Español. 
Regional del Quindío (CRQ) y al interventor del proyecto Túnel de la Línea, por irregularidades en sus obligaciones ${ }^{31}$.

2. Ruta del Sol ${ }^{32}$

Esta obra de $1.071 \mathrm{~km}$ busca conectar a Bogotá con la Costa Atlántica en menos tiempo, atravesando 8 departamentos y 39 municipios. El proyecto se adjudicó mediante el Contrato de Concesión 001 de 2010, al consorcio Commsa, que incumplió el contrato, por lo que, en una segunda licitación, fue adjudicado a Odebrecht, que corrió con la misma suerte. Actualmente se está realizando el tercer proceso de licitación.

La inversión total que se ha realizado en esta obra es de aproximadamente 7,5 billones de pesos, lo que equivale a unos 1.948.745.250.000€.

3. Puente Pumarejo

Esta obra tiene 3,25 km de longitud, y permitirá mejorar la comunicación entre los puertos de Santa Marta y Barranquilla. La construcción se inició el 19 de mayo de 2015 , y en este momento ya cuenta con un retraso del $26 \%$ de la obra ${ }^{33}$, por lo que se impuso una multa al consorcio SES por $158.497 .95 €^{34}$.

La inversión total que se ha realizado en la obra es de 202.055.775.32 $€^{35}$.

4. Puente Hisgaura

Esta obra fue contratada por un valor inicial de 20.797.009.31€ mediante Contrato de Obra n. ${ }^{\circ} 285$ de 2013; sin embargo, luego de varias adiciones el coste aumentó a $27.974 .367 .98 €$.

La obra actualmente está terminada; sin embargo, el Invías no la ha recibido porque "visualmente" denota baja calidad, lo que genera desconfianza en los usuarios y el Instituto, a pesar de haber cumplido con las pruebas estándares de resistencia ${ }^{36}$. Por su parte, el Instituto Nacional de Vías recibió el último informe de interventoría,

31 Sanciones, "Pliego de cargos a Invías por irregularidades con el Túnel de la Línea" https://www.dinero.com/ pais/articulo/pliego-de-cargos-a-invias-por-tunel-de-la-linea/251963, revista Dinero, 11 de febrero de 2017. Consultado agosto de 2019. Español.

32 Especiales Semana "La tragedia de la Ruta del Sol" https://especiales.semana.com/ruta-del-sol/, Revista Semana, 2019. Español.

33 Redacción Nacional, "Sacyr dice que aún no existe sanción en firme por retraso en la obra del Puente Pumarejo" https://www.elespectador.com/noticias/nacional/atlantico/sacyr-dice-que-aun-no-existe-sancionen-firme-por-retraso-en-la-obra-del-puente-pumarejo-articulo-755114, periódico El Espectador, 10 de mayo de 2018. Español

34 LAS2Orillas, "Los españoles de Sacyr le fallaron a los barranquilleros con el puente Pumarejo" https:// www.las2orillas.co/los-espanoles-de-sacyr-le-fallaron-los-barranquilleros-con-el-puente-pumarejo/, Periódico virtual LAs2Orillas, 20 de mayo de 2018. Español

35 Informe de Gestión 2018 - Instituto Nacional de Vías.

36 Rodríguez, María Alejandra (2019). "Puntos clave para entender quépasó en el polémico puente Hisgaura" https:// www.eltiempo.com/colombia/otras-ciudades/puntos-clave-para-entender-los-problemas-del-puentehisgaura-335034, Periódico El Tiempo, 07 de marzo de 2019. Español. 
y sobre este adelanta un tribunal de arbitramento con el contratista ${ }^{37}$, a fin de establecer si recibe o no la obra.

5. Así mismo, existe un informe mediante el cual la Agencia Nacional de Infraestructura, el Instituto Nacional de Vías y la Aerocivil informaron al entonces vicepresidente, Germán Vargas Lleras, que entre enero y marzo de 2015:

(...) la ANI aplicó como medida sancionatoria descuentos en el recaudo por peajes por 16.456 millones de pesos a los concesionarios que incumplieron los plazos de entrega de los tramos viales pactados, por fallas en pavimentos o puentes defectuosos.

Invías, a su vez, en igual lapso multó con más de 4.074 millones de pesos a firmas que subcontrataron irregularmente otras empresas para hacer las obras y no cumplir debidamente con los trabajos pactados.

La Aerocivil dispuso sanciones por 3.827 millones de pesos en igual periodo a contratistas, por malos trabajos en pistas, plataformas y retrasos en la entrega de obras de infraestructura aeroportuaria $^{38}$.

En suma, tenemos que, en el caso colombiano, si bien se ha hecho una inversión importante en el sector de infraestructura vial, también es cierto que no hay resultados favorables en términos de calidad; todo lo contrario, se evidencia una deficiencia importante al punto que alcanza el mismo nivel de economías menos desarrolladas.

Así mismo, los mecanismos sancionatorios, que tienen como finalidad exhortar al contratista al cumplimiento se usan con demasiada frecuencia, y aun así no logran disminuir el riesgo de incumplimiento, ya que puede haber una gran cantidad de contratos en proceso y de resoluciones sancionatorias demandadas en la jurisdicción.

Finalmente, se observa que el coste para el Estado en incumplimientos ha sido muy elevado, ya que la mayoría de los contratos que se encuentran en proceso son los seleccionados mediante licitación, que son los que implican una mayor inversión por parte del gobierno colombiano.

\section{iv. Garantías en el régimen colombiano: fundamento legal}

En el caso colombiano, los contratos públicos "deben obligatoriamente contener una cláusula de garantía con el objeto de respaldar el cumplimiento de las obligaciones

37 Instituto Nacional de Vías "Comunicado de Prensa" https://www.invias.gov.co/index.php/mas/sala/ noticias/3362-comunicado-de-prensa-nobiembre-2018, 06 de noviembre de 2018, Español.

38 El Tiempo, "Millonarias sanciones a contratistas que demoran obras" https://www.eltiempo.com/ archivo/documento/CMS-16566133, periódico El Tiempo, 17 de abril de 2017, Español. 
surgidas del contrato, cláusula que no puede estar estipulada por el acuerdo de las partes, como sucede en los contratos entre particulares, pues su inclusión es imperativa"39.

Dicha póliza se encuentra reglada por las siguientes normas:

- Ley 80 de 1993, "Por la cual se expide el Estatuto General de Contratación de la Administración Pública".

- Ley 1150 de 2007, "Por medio de la cual se introducen medidas para la eficiencia y la transparencia en la Ley 80 de 1993 y se dictan otras disposiciones generales sobre la contratación con Recursos Públicos".

- Decreto 1082 de 2015, "Por medio del cual se expide el Decreto Único Reglamentario del Sector Administrativo de Planeación Nacional".

\section{Clases de garantía}

En el artículo 7 de la Ley 1150 de 2007 se dispone que son tres los tipos de garantías que acepta la administración:

Art. $7^{\circ}$. De las garantías en la contratación. Los contratistas prestarán garantía única para el cumplimiento de las obligaciones surgidas del contrato. Los proponentes prestarán garantía de seriedad de los ofrecimientos hechos.

Las garantías consistirán en pólizas expedidas por compañías de seguros legalmente autorizadas para funcionar en Colombia, en garantías bancarias y en general, en los demás mecanismos de cobertura del riesgo autorizados por el reglamento para el efecto. Tratándose de pólizas, las mismas no expirarán por falta de pago de la prima o por revocatoria unilateral.

En complemento de la norma anteriormente citada, el artículo $110\left[{ }^{40}\right]$ del Decreto 1510 de 2013 señala expresamente las siguientes:

- Contrato de seguro.

- Fiducia mercantil de garantía (patrimonio autónomo).

- Garantía bancaria (cartas de crédito) ${ }^{41}$.

Empero, para nuestro estudio únicamente nos centraremos en el Contrato de seguro, que está estructurado como se muestra en la siguiente tabla.

39 Superintendencia Financiera de Colombia, Oficio de Radicación:2019067313-001-000, de fecha: 2019-06-19.

40 Modificado por el artículo 2.2.1.2.3.1.2. Decreto 1082 de 2015.

41 En los artículos 2.2.1.2.3.1.9 a 2.2.1.2.3.1.16 del Decreto 1082 de 2015, se establece la vigencia y los estándares mínimos del valor asegurado de las mismas. 


\begin{tabular}{|c|c|}
\hline $\begin{array}{l}\text { Cobertura } \\
\text { en etapa } \\
\text { contractual }\end{array}$ & $\begin{array}{l}\text { 1. Buen manejo y correcta inversión del anticipo: } \\
\text { - Uso indebido, apropiación o no inversión del anticipo. } \\
\text { - Su cobertura debe ser del } 100 \% \text { del valor entregado como anticipo. } \\
\text { 2. Devolución del pago anticipado: } \\
\text { - Cubre la devolución del pago anticipado, que se puede solicitar } \\
\text { adicional al incumplimiento. } \\
\text { - Su cobertura debe ser del } 100 \% \text { del valor entregado como pago } \\
\text { anticipado. } \\
\text { 3. Incumplimiento del contrato: } \\
\text { - El incumplimiento total o parcial del contrato. } \\
\text { - El cumplimiento tardío o defectuoso del contrato. } \\
\text { - Los daños imputables al contratista por entregas parciales de la obra, } \\
\text { cuando el contrato no prevé entregas parciales. } \\
\text { - El pago del valor de las multas y de la cláusula penal pecuniaria. }\end{array}$ \\
\hline $\begin{array}{l}\text { Cubrimiento } \\
\text { etapa } \\
\text { postcontractual }\end{array}$ & $\begin{array}{l}\text { 1. Estabilidad y calidad de la obra. Este amparo cubre cualquier tipo de } \\
\text { daño o deterioro, imputable al contratista, sufrido por la obra entregada a } \\
\text { satisfacción. }\end{array}$ \\
\hline Exenciones & $\begin{array}{l}\text { 1. Causa extraña: Fuerza mayor y Caso fortuito. } \\
\text { 2. Casos en los que procedan eximentes de responsabilidad. } \\
\text { 3. Excesos sobre el valor asegurado. } \\
\text { 4. La responsabilidad extracontractual, a menos que el contratista tenga } \\
\text { contratada una póliza de este tipo. } \\
\text { 5. Negligencia por parte de la Administración. } \\
\text { 6. Daños causados por el deterioro normal de la obra. }\end{array}$ \\
\hline $\begin{array}{l}\text { Cláusulas } \\
\text { excepcionales } \\
\text { de la } \\
\text { administración }\end{array}$ & $\begin{array}{l}\text { 1. Interpretación unilateral de los contratos, en caso de que exista } \\
\text { discrepancia sobre su sentido y no se logre llegar a un acuerdo. No } \\
\text { procede una vez liquidado. } \\
\text { 2. Modificación unilateral del contrato para evitar la paralización o afectación } \\
\text { grave de la obra, mediante acto administrativo motivado. } \\
\text { 3. Terminación unilateral o caducidad, procede cuando hay una afectación } \\
\text { grave de la obra. Se hará mediante decisión motivada. } \\
\text { 4. Cláusula de cesión del contrato a la aseguradora para que esta culmine el } \\
\text { contrato. }\end{array}$ \\
\hline $\begin{array}{l}\text { Cláusulas } \\
\text { prohibidas }\end{array}$ & $\begin{array}{l}\text { 1. Las que establezcan franquicias, coaseguros obligatorios, y cualquier otra } \\
\text { forma que exima de parte del siniestro a la compañía de seguros. } \\
\text { 2. No hay lugar a que se dé por terminado el contrato de seguro por parte de } \\
\text { la compañía de seguros alegando cesación del pago de la prima. } \\
\text { 3. No se podrá alegar como excepción inexactitudes en la relación } \\
\text { contractual con el contratista. } \\
\text { 4. Cláusula de proporcionalidad en caso de siniestro parcial. }\end{array}$ \\
\hline
\end{tabular}




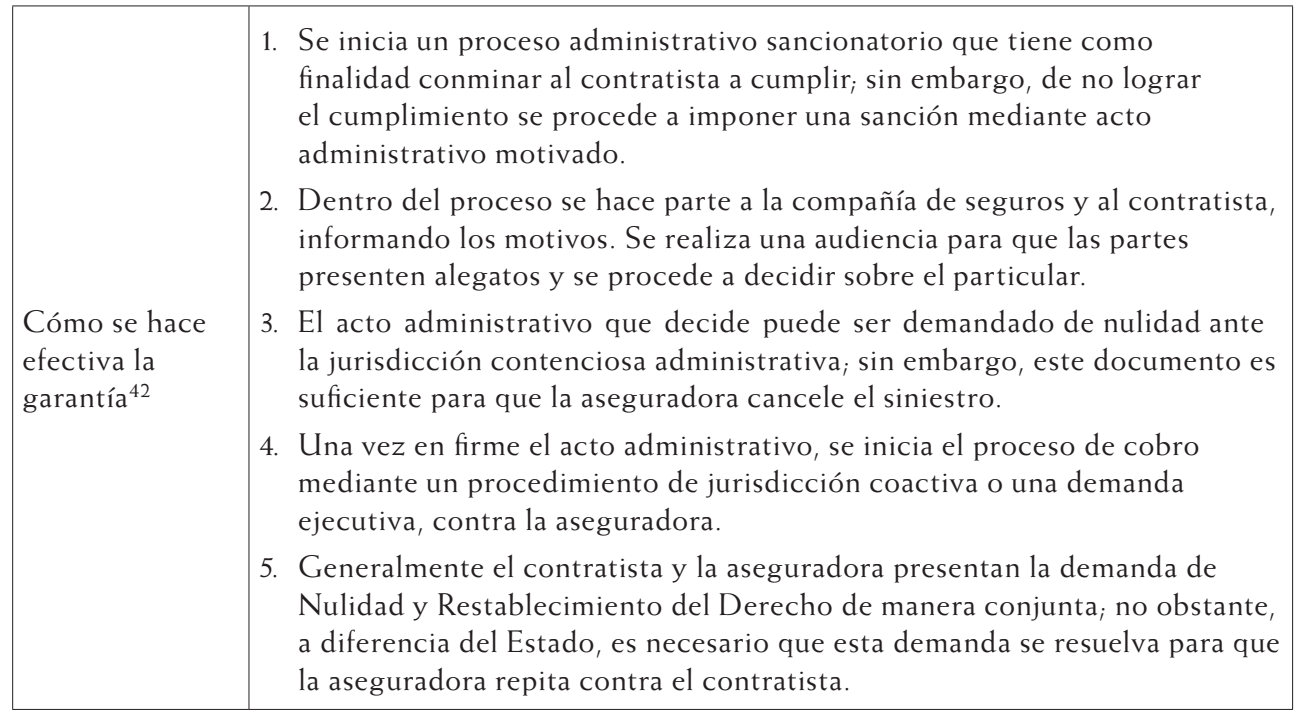

\section{ANÁLISIS DE LA GARANTÍA DE CUMPLIMIENTO COLOMBIANA}

Dentro de la estructura de la Garantía de cumplimiento exigida por el Estado colombiano en los contratos de obra, encontramos las siguientes deficiencias:

\section{i. Aumenta el riesgo moral del contratista}

\section{a) Probibición de deducibles}

Uno de los puntos en los que se aprecia un aumento importante del riesgo moral es en la probibición de franquicias, deducibles, y en general cualquier mecanismo que exima total o parcialmente a la compañía de seguros, teniendo en cuenta que, como hemos mencionado en líneas anteriores, el riesgo moral se puede menguar haciendo al asegurado o al beneficiario (si son la misma persona) partícipes de parte del daño en caso de que ocurriera el siniestro.

Estos mecanismos tienen dos efectos en la disminución del riesgo: en primer lugar, la posibilidad de que el siniestro tenga un impacto directo en el patrimonio del contratista es un incentivo para que este invierta en precaución para disminuir el riesgo. Sin embargo, esta propensión a evitar la ocurrencia del daño se pierde cuando la aseguradora asume el $100 \%$ de la responsabilidad patrimonial, como es el caso de la póliza colombiana.

42 Ley 1437 de 2011, "Por la cual se expide el Código de Procedimiento Administrativo y de lo Contencioso Administrativo", Capítulo III "Del Procedimiento Administrativo Sancionatorio", arts. 47 al 52 . 
Lo anterior en el entendido de que el contratista intentará mantener sus costes lo más bajo que le sea posible, ya que, como ya se ha dicho, su utilidad esperada es: P-C, y si C llega a ser mayor que $\mathrm{P}$, no celebrará el contrato. No obstante, la inversión en precaución representa un aumento de costes para el contratista $(C)$, por lo que la única razón para invertir en mermar el riesgo es que sea menos costoso prevenir que asumir el daño y que dicho aumento de $\mathrm{C}$ no haga que sea $\mathrm{C}>\mathrm{P}$. Pero, en caso de que el coste de la ocurrencia del daño para el contratista sea igual a cero, no tendrá incentivos para invertir en precaución.

En segundo lugar, el deducible es un mecanismo para fomentar la disminución progresiva del riesgo en los asegurados. En el sentido que el porcentaje de participación en el daño puede variar favorable o desfavorablemente según la actitud que este haya tenido frente a la prevención del riesgo.

Por ejemplo, en los casos de seguro de coches, las personas que tienen historiales con menos accidentes y multas de tránsito pueden tener el beneficio de que se disminuye su porcentaje de participación en el riesgo, mientras que quienes tienen antecedentes de un alto grado de accidentalidad y multas se les aumenta el deducible, para que, al ver más comprometido su patrimonio se sientan motivados a invertir en prevenir la ocurrencia del riesgo.

En suma, la prohibición de figuras como la franquicia y los deducibles aumentan el riesgo moral del contratista y propicia niveles altos de riesgo, por lo que el contratista preferirá mantenerse en el límite de tolerancia o incumplirá el contrato, ya que le es menos costoso.

\section{b) Cobertura del dolo}

Por otra parte, la póliza también cubre el dolo de los contratistas. Llama sobre todo la atención lo dispuesto en el artículo 2.2.1.2.3.1.7 del Decreto 1082 de 2015, en el que se establece que el amparo debe cubrir "los perjuicios sufridos por la Entidad Estatal con ocasión de: (i) la no inversión del anticipo; (ii) el uso indebido del anticipo; y (iii) la apropiación indebida de los recursos recibidos en calidad de anticipo" (destacado fuera del original). Esto, en el entendido de que la ocurrencia de estos eventos dependerá única y exclusivamente de la voluntad del contratista.

El anticipo es el dinero que el contratante entrega al contratista para dar inicio a la obra, por lo que es propiedad del constructor en la medida en que se justifique el uso de estos dineros única y exclusivamente en la ejecución del contrato, y correcta su inversión es responsabilidad del contratista.

Por lo que si la garantía ampara el no uso, el uso indebido y la apropiación, se están asegurando actos dolosos o de culpa grave imputables al contratista, en contradicción del principio general señalado en el artículo 1055 del Código de Comercio Colombiano que dispone que "el dolo, la culpa grave y los actos meramente potestativos del tomador, asegurado o beneficiario son inasegurables. Cualquier estipulación en contrario 
no producirá efecto alguno, tampoco lo producirá la que tenga por objeto amparar al asegurado contra las sanciones de carácter penal o policivo".

Esta situación, que, aunque protege efectivamente al Estado frente a la pérdida del presupuesto invertido en calidad de anticipo en la obra, puede aumentar excesivamente el riesgo moral en el contratista, puesto que con un cubrimiento sobre el $100 \%{ }^{43}$ de los dineros entregados como anticipo, se traslada el total de la responsabilidad patrimonial del contratista a la aseguradora.

Lo mismo ocurre con la prohibición de dar por terminado el contrato de seguro por parte de la compañia de seguros alegando cesación del pago de la prima. Esta restricción implica que, incluso cuando el contratista cese el pago de la prima, la aseguradora tendrá la responsabilidad de asumir el daño en caso de que sobrevenga el siniestro, lo cual es, claramente, una cobertura del dolo del contratista, ya que el no cancelar la prima es un acto potestativo.

Es decir que el contratista se verá aún más exonerado de su responsabilidad patrimonial, y no solo traslada la carga del daño a un tercero (la aseguradora) sino que, además, no es necesario que realice el pago de la prima para que la compañía de seguros asuma el daño.

La cobertura del dolo implica que se protege al contratista de su intensión deliberada de causar un daño o un detrimento, lo que hace que el riesgo de ocurrencia el siniestro y el riesgo moral sean muy altos.

En este punto, para que se evite la comisión del daño se debe evaluar que es más ventajoso para el contratista: 1) cumplir el contrato, 2) cumplir y asumir el coste administrativo del pago de la póliza, o 3) bien incumplir el contrato. Entre estas opciones, ceteris paribus, el contratista preferirá la 1 o la 3, ya que son las que implican menor coste.

Sin embargo, sobre el dolo y los contratos de seguros, pese a la prohibición general que existe, se puede actuar frente a la cobertura del dolo de diferentes formas ${ }^{44}$. Esto dependerá del tipo de póliza que se contrata, así: si son seguros voluntarios, tiene sentido la exoneración de la compañía de seguros, si el daño se cometiere por actos dolosos imputables al asegurado.

Por otra parte, en los seguros obligatorios, como es el caso de las pólizas de cumplimiento en contratos de obra, se ha adoptado la posición de que la compañía de seguros asumirá el daño, sin perjuicio del recobro que puede ejercer sobre el asegurado. Esto se debe a que se tiende a salvaguardar el fin indemnizatorio de la póliza, y que su obligatoriedad obedece a la necesidad de proteger a las posibles víctimas de los daños ${ }^{45}$.

No obstante, la efectividad de esta medida de recobro dependerá de si la compañía de seguros cuenta con medios idóneos para lograr el reintegro y además de la solvencia económica del contratista.

44 Gómez Pomar, Fernando y Arquillo Colet, Begoña (2000). "Daños dolosos y seguro". InDret Revista para el Análisis del Derecho, marzo. España. 


\section{c) Proceso de recobro}

Así mismo, se denota que el proceso para que la compañía de seguros pueda pedir el reintegro del pago de los daños es extenso y dispendioso:

Para que el contratante pueda hacer efectiva la póliza debe iniciar un proceso sancionatorio, dentro del cual se llama tanto al contratista como a la compañía de seguros para que ejerzan su defensa. Luego de lo cual, se expide un acto administrativo sancionatorio en el que se declara el motivo de la sanción (incumplimiento parcial o definitivo, calidad y estabilidad de la obra, etc.).

Este Acto Administrativo Sancionatorio es el título ejecutivo que atribuye al contratante la facultad de hacer efectiva la póliza directamente, sin necesidad de acudir a un proceso judicial.

No obstante, es posible demandar la legalidad de la sanción mediante una acción de Nulidad y Restablecimiento del Derecho ${ }^{46}$. Es necesario aclarar que para que proceda esta acción es necesario que se demuestre el daño que se pretende resarcir, razón por la cual se debe efectuar el pago de la sanción, entendiendo dicho pago como el daño causado.

En ese orden de ideas, está claro que para que la compañía de seguros inicie el proceso de recobro contra el contratista, debe existir sentencia en firme de la acción de Nulidad y Restablecimiento del Derecho.

Ahora bien, el procedimiento puede que no presente problemas en sí mismo, pero es posible que tenga consecuencias a largo plazo, ya que el contratista no asumirá la responsabilidad patrimonial después de que se declare su incumplimiento, sino que tendrá que atravesar todo un proceso judicial, que puede tardar en promedio unos 336 días para que exista un pronunciamiento de fondo ${ }^{47}$.

Por lo tanto, todas estas exigencias procedimentales necesarias para hacer el recobro pueden aumentar significativamente el Riesgo Moral del contratista, ya que, entre más largo sea el tiempo para dar solución al proceso, hay más posibilidades de que pueda liberarse de su responsabilidad patrimonial.

Un ejemplo de ello es que en este término el contratista pueda declararse insolvente; y si el Estado se lo permite fácilmente, hay un alto riesgo de evasión de obligaciones, lo que por supuesto incluye el reintegro a las compañías de seguros.

46 Baptista Sánchez, Néstor Raúl (2015). "Los motivos y las finalidades de la acción de nulidad y de la acción de nulidad y restablecimiento del derecho: El debate subsiste", Revista Virtual Via Inveniendi et Iudicandi, Bogotá, Colombia. En este documento se expone claramente que la acción de nulidad puede ser interpuesta por cualquier persona, ya que se refiere a actos administrativos generales, mientras que la nulidad y restablecimiento del derecho, solo puede ser interpuesta por el afectado, pues aplica a actos administrativos concretos.

47 Consejo Superior de la Judicatura "Resultado del Estudio de Tiempos Procesales", 2016, Bogotá, Colombia. 


\section{d) Consecuencias reputacionales}

Podría pensarse que el actuar del contratista en estos casos se puede ver frenado por razones reputacionales, o por temor a no poder celebrar futuros contratos con el Estado. No obstante, debido a la falta de fortalecimiento de las instituciones este no es un impedimento real.

En el artículo $8^{[48]}$, de la Ley 80 de 1993, se enumeran las causales que inhabilitan y hacen incompatible a las personas naturales y jurídicas para participar en procesos

48 Art. 8- De las inhabilidades e incompatibilidades para contratar.

1. Son inhábiles para participar en licitaciones o concursos y para celebrar contratos con las entidades estatales:

a) Las personas que se hallen inhabilitadas para contratar por la Constitución y las leyes.

b) Quienes participaron en las licitaciones o concursos o celebraron los contratos de que trata el literal anterior estando inhabilitados.

c) Quienes dieron lugar a la declaratoria de caducidad.

d) Quienes en sentencia judicial hayan sido condenados a la pena accesoria de interdicción de derechos y funciones públicas y quienes hayan sido sancionados disciplinariamente con destitución.

e) Quienes sin justa causa se abstengan de suscribir el contrato estatal adjudicado.

f) Los servidores públicos.

g) Quienes sean cónyuges o compañeros permanentes y quienes se encuentren dentro del segundo grado de consanguinidad o segundo de afinidad con cualquier otra persona que formalmente haya presentado propuesta para una misma licitación o concurso.

h) Las sociedades distintas de las anónimas abiertas, en las cuales el representante legal o cualquiera de sus socios tengan parentesco en segundo grado de consanguinidad o segundo de afinidad con el representante legal o con cualquiera de los socios de una sociedad que formalmente haya presentado propuesta, para una misma licitación o concurso.

i) Los socios de sociedades de personas a las cuales se haya declarado la caducidad, así como las sociedades de personas de las que aquellos formen parte con posterioridad a dicha declaratoria. (...).

2. Tampoco podrán participar en licitaciones o concursos ni celebrar contratos estatales con la entidad respectiva:

a) Quienes fueron miembros de la junta o consejo directivo o servidores públicos de la entidad contratante. Esta incompatibilidad solo comprende a quienes desempeñaron funciones en los niveles directivo, asesor o ejecutivo, y se extiende por el término de un (1) año, contado a partir de la fecha del retiro.

b) Las personas que tengan vínculos de parentesco, hasta el segundo grado de consanguinidad, segundo de afinidad o primero civil con los servidores públicos de los niveles directivo, asesor, ejecutivo o con los miembros de la junta o consejo directivo, o con las personas que ejerzan el control interno o fiscal de la entidad contratante.

c) El cónyuge, compañero o compañera permanente del servidor público en los niveles directivo, asesor, ejecutivo, o de un miembro de la junta o consejo directivo, o de quien ejerza funciones de control interno o de control fiscal.

d) Las corporaciones, asociaciones, fundaciones y las sociedades anónimas que no tengan el carácter de abiertas, así como las sociedades de responsabilidad limitada y las demás sociedades de personas en las que el servidor público en los niveles directivo, asesor o ejecutivo, o el miembro de la junta o consejo directivo, o el cónyuge, compañero o compañera permanente o los parientes hasta el segundo grado de consanguinidad, afinidad o civil de cualquiera de ellos, tenga participación o desempeñe cargos de dirección o manejo. 
de licitación y, en general, para contratar con el Estado; sin embargo, del tenor literal de la norma se observa que el estar inmerso en un proceso sancionatorio, o haber sido sancionado, no se mencionan dentro de estas causales, por lo que no es un impedimento para contratar.

Es decir, se remueve el riesgo reputacional que puede condicionar futuras relaciones contractuales con la administración, y además se aumenta el riesgo de incumplimiento en futuros contratos.

\section{ii. Disminución de costes del contratista en detrimento del Estado o de la aseguradora}

Como ya se ha mencionado en diversas ocasiones, el contratista intentará disminuir los costes siempre que le sea posible para aumentar su utilidad esperada. Sin embargo, este comportamiento no siempre es beneficioso para la contraparte.

En el diseño de esta garantía hemos identificado tres situaciones en las que el contratista puede disminuir costes:

1. Generalmente, el contratista incluirá en el precio el coste que le representa el seguro, ya que sin este es imposible celebrar el contrato en el sistema colombiano. No obstante, como ya se ha expuesto, la compañía de seguros está obligada a cancelar el valor del siniestro incluso si el contratista ha cesado en el pago de la póliza.

Este panorama puede propiciar que el contratista opte por prescindir del pago de la prima, y así disminuir sus costes. Esto, en el entendido de que, ceteris paribus, no hay una consecuencia que lo desincentive de incumplir su obligación con la compañía de seguros.

2. En vista de que no hay lugar a deducibles, y por lo tanto no hay responsabilidad patrimonial directa en caso de que acaezca el siniestro, el contratista simplemente optará por ahorrarse el coste de invertir en prevención y actuará únicamente según sus intereses contractuales.

3. Por supuesto, otra forma de deducir los costes será en la calidad de la obra de una forma imperceptible, manteniéndose en el límite de tolerancia.

En el primer caso, el ahorro en costes se hace en detrimento de la compañía de seguros, que es la que soporta el daño causado. En el segundo y tercer caso, el menoscabo es para el Estado, ya que se aumenta el riesgo de incumplimiento y la estabilidad de la obra, respectivamente.

e) Los miembros de las juntas o consejos directivos. Esta incompatibilidad solo se predica respecto de la entidad a la cual prestan sus servicios y de las del sector administrativo al que la misma esté adscrita o vinculada. 


\section{iii. Aumento de costes para el Estado}

Así mismo, del diseño de la póliza se desprenden costes adicionales para el Estado, que llegan a ser innecesarios:

\section{a) Interventoría}

Dada la prohibición de los deducibles, el contratante se ve obligado a prescindir de estos y adoptar otros mecanismos para reducir el riesgo de la ocurrencia del siniestro, como la interventoría (monitoring), que es un contrato por medio del cual se ejerce la vigilancia y se hace seguimiento de la ejecución del contrato por parte de un tercero; no obstante, este mecanismo es mucho más costoso para el Estado, ya que representa un nuevo proceso de selección, nueva relación contractual, y un precio adicional.

Además, el Contrato de interventoría no siempre surte los efectos de prevención del riesgo deseado, ya que este también presenta los mismos problemas de agencia y asimetría de la información que el contrato de obra. Por lo que es una alternativa ineficiente.

De hecho, en este caso vale la pena ponderar si, en caso de que se permitiera el uso de deducibles, el porcentaje del daño que le correspondería al contratista, compensa el coste en que se incurre en celebrar un contrato de interventoría, o si es mucho más costoso. Y así establecer la pérdida real en caso de que el contratista decida no cancelarlo.

\section{b) Aumento del precio}

Para la aseguradora, la prohibición de que rehúse cancelar la indemnización con ocasión de la omisión del pago de la prima por parte del contratista se traduce en un aumento de su riesgo. Esto, teniendo en cuenta que, de no cumplir con la obligación de cancelar la prima, la compañía de seguros terminaría asumiendo la ocurrencia del siniestro, sin recibir la compensación económica que le corresponde por ello.

Lo que ocurriría en torno a este panorama puede ser que: i) las compañías de seguro dejen de considerar rentable este tipo de seguros, ya que representa un alto riesgo y adicionalmente pierden el precio, por lo que en su utilidad esperada (dependiendo de la probabilidad) el coste puede ser más alto que el precio, o bien ii) que se acuerde cancelar la prima en un solo pago.

Esta última parece ser una solución bastante razonable; sin embargo, el cancelar la prima en una sola cuota aumenta de forma considerable el coste de inicio de ejecución para el contratista. El inconveniente es que, este aumento de coste será internalizado por el contratista aumentando el precio, lo que a su vez se traduce en un aumento de la inversión para el contratante.

En suma, el aumento del precio, y así mismo el coste del contrato, sería innecesario si se adoptaran medidas sancionatorias para disminuir el riesgo de no pago de la prima 
y el riesgo moral. Asimismo, está claro que el poder omitir el pago de la prima es muy atractivo para el contratista, quien siempre buscará disminuir los costes.

\section{c) Cláusula de proporcionalidad}

La regla de la proporcionalidad deviene de la función indemnizatoria del seguro, que prohíbe el enriquecimiento mediante el cobro de una póliza, y hace que se limite a resarcir el daño acaecido, para devolver a la víctima al estado en que se encontraba antes de la ocurrencia del siniestro.

Por lo que la aseguradora está obligada a pagar únicamente en proporción al daño, al valor asegurado o a las primas que han sido canceladas, según se haya pactado.

Ahora bien, en cuanto al contrato de obra pública, se prohíbe el uso de cláusulas de proporcionalidad en lo que a cláusulas penales se refiere; sin embargo, hay pronunciamientos de Colombia Compra Eficiente en los que se establece que, para este caso, se debe tener en cuenta el nivel de cumplimiento en el que se encuentra la obra ${ }^{49}$.

Esta situación representa un aumento del riesgo de las aseguradoras, por lo que aumentarán el valor de la prima para así estar en capacidad de asumir el coste de que se cobre un siniestro más allá de la proporcionalidad; este incremento repercutirá en los costes del contratista, quien a su vez lo internalizará aumentando el precio para el contratante.

En conclusión, puede llevar consigo un aumento innecesario del precio que no es más que una administración indeficiente de recursos.

\section{iv. Aspectos a mejorar}

En suma, según las condiciones expuestas, es más beneficioso para el contratista incumplir el contrato, en el sentido de que tiene la posibilidad de apropiarse tanto del anticipo como del pago anticipado, sin incurrir en los costes de la obra ni de la prima del seguro, y adicionalmente a ello, la responsabilidad patrimonial suscitada por sus actos será asumido por la aseguradora en un $100 \%$, pues no se está haciendo partícipe del daño al contratista con un deducible, lo que incrementa aún más el problema del riesgo moral.

Ahora bien, está claro que el principal problema de la garantía colombiana es que, en su excesiva protección del erario, ha liberado al contratista completamente de su responsabilidad patrimonial, y con ello ha aumentado su riesgo moral.

En ese orden de ideas, es menester que las exigencias legales en el diseño de la póliza se modifiquen a fin de que el contratista se sienta más comprometido a invertir

49 Aguilar, Natalia (2017). "¿Es posible pactar la cláusula de proporcionalidad en el seguro de cumplimiento en favor de Entidades Estatales?" https://www.colombiacompra.gov.co/content/es-posible-pactar-la-clausula-deproporcionalidad-en-el-seguro-de-cumplimiento-en-favor-de, Colombia Compra Eficiente, 2 de julio de 2017. Consultado julio 2019. Español. 
en prevención y disminuir el riesgo de incumplimiento. Es por ello que hemos considerado que la garantía debe tener los siguientes cambios:

Es necesario separar la responsabilidad patrimonial del material: por una parte el contratista puede garantizar el buen uso de los recursos, la conservación del seguro (pago de la prima) y la calidad de la obra mediante una garantía personal. Nos parece sobre todo acertado el modelo de los surety bonds en Estados Unidos, o los seguros de fianza.

Sin embargo, en Colombia no se reconoce a la fianza como seguro, ya que, según la Superintendencia Financiera de Colombia ${ }^{50}$, esta carece del carácter indemnizatorio propio de las pólizas de seguro, razón por la cual no se acepta como garantía en los contratos públicos.

No obstante, consideramos que las garantías personales pueden tener los siguientes efectos en la ejecución del contrato:

i) Se disminuye el riesgo moral, ya que el contratista asume directamente la responsabilidad patrimonial de sus actos y muy probablemente invertirá en precaución.

ii) Si bien es un mecanismo costoso, puede que sea mejor celebrar contratos de obra con personas que cuenten con amplia solvencia económica, y de esta forma se disminuye las posibilidades de que el contratista sea más propenso al riesgo por falta de patrimonio.

iii) Es posible que haya un impacto positivo en la calidad de la obra.

iv) Hemos inferido que es mucho más fácil para el contratante hacer el cobro de la indemnización, que para la compañía de seguros. Con este mecanismo, se evita el proceso dispendioso de recobro para la aseguradora, y el Estado obtiene la indemnización directamente del responsable.

v) Contemplamos que en este panorama el contratista puede aumentar el precio de la obra, lo que representa un aumento de costes para el contratante. Sin embargo, es menos probable un incumplimiento.

Adicionalmente, es necesario establecer un sistema de consecuencias reputacionales, que condicionen futuros contratos para personas que han incurrido en incumplimientos y para quienes haya sido necesario iniciar varios procesos sancionatorios para lograr el cumplimiento.

Estas medidas ayudan a reglar de manera más eficiente el comportamiento de los contratistas, ya que, si existe la intención de mantener relaciones comerciales a lo largo del tiempo, se verá forzado a cumplir de manera satisfactoria el contrato. Además, se evita el riesgo de que haya una cadena de incumplimientos.

De otra parte, consideramos que la responsabilidad material de la obra puede recaer directamente sobre las aseguradoras. Es decir, en caso de que no se cumpla

50 Superintendencia Financiera de Colombia, Oficio de Radicación: 2019067313-001-000, de fecha: 2019-06-19. 
con el contrato, la compañía de seguros debe asegurar la culminación de la obra, y no regresar el dinero; esto teniendo en cuenta que es de más utilidad para el Estado la obra que el rembolso del dinero.

Es claro que adicionar la construcción de obras al objeto social de las aseguradoras puede ser incluso más costoso que asumir la indemnización, pero cqué pasaría si en vez de construir por sí misma, realizara la selección de un nuevo contratista bajo su responsabilidad?

En este modelo de póliza funcionaría complementariamente a la garantía personal

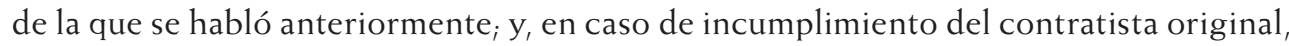
la compañía de seguros se encargaría de seleccionar un nuevo contratista que lleve a cabo el proyecto con el dinero restante de la obra ${ }^{51}$.

Algunas de las ventajas de este diseño de póliza:

- Es un riesgo que es mucho menos costoso de cubrir en caso de incumplimiento. Puesto que las compañías de seguros tendrán que conformar un comité de selección que designe al nuevo contratista. Este comité es un coste fijo, pues con uno solo que se conforme se puede suplir una gran cantidad de pólizas.

- También representa una ventaja para el contratante, quien obtendrá la obra contratada y no el rembolso, lo cual es mucho menos costoso. Esto teniendo en cuenta que, en caso de incumplimiento, el Estado tendrá que iniciar un nuevo proceso de licitación y selección que le representa un coste adicional y retrasa la obra.

- Así mismo, el fracaso del contratista seleccionado se traduce en la responsabilidad patrimonial de la aseguradora, con lo cual intentará que la selección sea lo más eficiente posible, ya que de esto depende que el cubrimiento del riesgo sea más o menos costoso.

Por supuesto, este modelo requiere una estructuración más detallada, pero consideramos que es un punto de partida para el diseño de una póliza que disminuya el problema del riesgo moral y permita un aprovechamiento más eficiente de los recursos del Estado.

\section{CONCLUSIONES}

En el presente trabajo hemos logrado establecer que el contrato de obra es en sí mismo fuente de riesgo moral, que surge debido a la asimetría de la información entre contratante y contratista, a su funcionamiento similar a la agencia administrativa, y a que las partes siempre buscarán maximizar sus beneficios con el contrato, por lo que se hace necesario incluir un seguro para garantizar el cumplimiento que, a su vez, también es fuente de riesgo moral.

51 En el entendido de que el contratante irá desembolsando el dinero periódicamente, debe contar con un patrimonio restante, y adicionalmente el dinero de la garantía personal del contratista incumplido. 
Así mismo, se determinó que el efecto que tendrá la póliza frente al riesgo moral y al cumplimiento dependerán de su diseño. Sin embargo, en el caso colombiano la póliza está diseñada de tal manera que, en ninguna circunstancia, el Estado pierda la inversión realizada; tal inclinación queda manifiesta cuando se obliga a la compañía de seguros a retornar el dinero al contratante en casos de dolo e invalidez contractual (no pago de la prima). Lo cual tiene efectos adversos: aumento del riesgo moral, aumento del coste para el contratista, y la posibilidad de que el contratista disminuya los costes administrativos y la calidad de la obra.

También pudimos poner de presente que los efectos de la póliza se reflejan en la realidad colombiana, donde la calidad de las vías es bastante deficiente y además hay grandes pérdidas del erario por incumplimientos. De igual manera, hemos establecido que la mayor cantidad de incumplimiento se da en los contratos seleccionados mediante procesos de licitación, que además son los que requieren mayor inversión por parte del Estado.

Por último, establecimos que, para mejorar esta situación, es necesario que el contratista tenga responsabilidad patrimonial directa de sus incumplimientos, así como que la compañía de seguros, en vez de reintegrar el dinero, se haga cargo de culminar el objeto del contrato.

No obstante, es claro que no hemos podido abarcar todos los temas con la profundidad que merecen y quedan varias cuestiones irresueltas, como:

1) Realizar un análisis de datos más detallado y profundo, mediante el que se pueda establecer qué variables influyen en el incumplimiento del contratista, como, por ejemplo: el valor de la obra, el tipo de póliza, el nivel de responsabilidad que recae sobre el contratista, etc.

2) Hacer una estructura más completa del modelo de póliza propuesta, haciendo el análisis necesario para establecer si sus efectos serán los deseados.

3) Analizar el comportamiento del contratista frente al incumplimiento, a fin de establecer si existe un comportamiento estratégico de su parte.

En suma, hemos concluido que la garantía de cumplimiento en Colombia aumenta el problema del riesgo moral y es ineficiente, y puede que incluso propicie el incumplimiento del contratista.

\section{REFERENCIAS}

"The Global Competitiveness Report 2018: Insigbt report", World Economic Forum (2019).

Acta Informe de Gestión, Carlos Alberto García Montes 2018 - Instituto Nacional de Vías (2018). Cohen, Alma \& Dehejia, Rajeev (2004). "The Effect Of Automobile Insurance and Accident Liability Laws On Traffic Fatalities", J. L. \& ECON. 357.

Decreto 1082 de 2015 "Por medio del cual se expide el Decreto Único Reglamentario del Sector Administrativo de Planeación Nacional". 
Gamazo Chillón, Juan Carlos. Comportamiento Burocrático y Presupuestación pública, Dirección General de Ciencia y Tecnología. Buenos Aires, Argentina.

Ley 1150 de 2007 "Por medio de la cual se introducen medidas para la eficiencia y la transparencia en la Ley 80 de 1993 y se dictan otras disposiciones generales sobre la contratación con Recursos Públicos".

Ley 1437 de 2011, "Por la cual se expide el Código de Procedimiento Administrativo y de lo Contencioso Administrativo".

Ley 80 de 1993 "Por la cual se expide el Estatuto General de Contratación de la Administración Pública".

LÓPEZ SAAVEDRA, DOMINGO (2008). Revista de responsabilidad civil y seguros: publicación mensual de doctrina, jurisprudencia y legislación.

MAnRIQUe, Carlos E. (1998). La fiducia de garantía, Ediciones Jurídicas Gustavo Ibáñez y Universidad de los Andes, Bogotá.

Krugman, Paul y Wells, Robin, "Introducción a la economía: Microeconomía, 2006, Editorial Reverté.

OMrI, Ben-ShaHAR \& KYlE D. LOgUE (2012). "Outsourcing Regulation: How Insurance Reduces Moral Hazard", Michigan Law Review 197.

Rodríguez-Arana Muñoz, Jaime y Álvarez Bairbeto, Francisco JaVier (1997). El régimen de las garantías para contratar con la administración pública, Actualidad Administrativa, España.

SuÁREZ, GonZAlo (2009). La nueva contratación pública, 1² Edición. Legis Editores S.A, Bogotá.

Superintendencia Financiera de Colombia, Oficio de Radicación:2019067313-001-000, de fecha: 2019-06-19.

Vallejo, Felipe (2007). "Responsabilidad Profesional en Cuanto a la Construcción de Obras", Revista Derecho del Estado, Colombia. 